Review Article

\title{
Natural Remedies for the Treatment of Beta-Thalassemia and Sickle Cell Anemia-Current Status and Perspectives in Fetal Hemoglobin Reactivation
}

\author{
Noel Yat Hey $\mathrm{Ng}^{1}$ and Chun Hay $\mathrm{Ko}^{2,3}$ \\ ${ }^{1}$ School of Life Sciences, The Chinese University of Hong Kong, Shatin, New Territories, Hong Kong \\ ${ }^{2}$ Institute of Chinese Medicine, The Chinese University of Hong Kong, Shatin, New Territories, Hong Kong \\ ${ }^{3}$ CUHK Shenzhen Research Institute, The Chinese University of Hong Kong, Shenzhen, Hong Kong \\ Correspondence should be addressed to Chun Hay Ko; gohey@cuhk.edu.hk
}

Received 18 April 2014; Revised 21 July 2014; Accepted 25 July 2014; Published 2 October 2014

Academic Editor: David Murphy

Copyright ( 2014 N. Y. H. Ng and C. H. Ko. This is an open access article distributed under the Creative Commons Attribution License, which permits unrestricted use, distribution, and reproduction in any medium, provided the original work is properly cited.

For the treatment of $\beta$-thalassemia and sickle cell disease (SCD), pharmacological induction of fetal hemoglobin (HbF) production may be a promising approach. To date, numerous studies have been done on identifying the novel HbF-inducing agents and understanding the underlying mechanism for stimulating the HbF production. In this review, we have summarized the identified $\mathrm{HbF}$-inducing agents by far. By examining the action mechanisms of the HbF-inducing agents, various studies have suggested that despite the ability of stimulating $\mathrm{HbF}$ production, the chemotherapeutic agents could not be practically applied for treating $\beta$ hemoglobinopathies, especially $\beta$-thalassemia, due to the their cytotoxicity and growth-inhibitory effect. Owing to this therapeutic obstacle, much effort has been put on identifying new HbF-inducing agents from the natural world with the combination of efficacy, safety, and ease of use. Therefore, this review aims to (i) reveal the novel screening platforms for identifying potential inducers with high efficiency and accuracy and to (ii) summarize the new identified natural remedies for stimulating HbF production. Hopefully, this review can provide a new insight into the current status and future perspectives in fetal hemoglobin reactivation for treating $\beta$-thalassaemia and SCD.

\section{Introduction}

Genetic disorders caused by mutations in the $\beta$-globin gene are widely known as the human $\beta$-hemoglobinopathies, in which $\beta$-thalassemia and sickle cell disease (SCD) are the most prevalent ones, particularly in the Mediterranean, Africa, and Southeast Asia, leading to great mortality and morbidity $[1-4]$. The high occurrence of the $\beta$-thalassemia and SCD mutations is due to the reason that both cause mild severity of malarial infection in the heterozygous state [5-7]. However, in the homozygous state, these mutations shorten the lives of affected ones [5].

$\beta$-thalassemia is caused by the inherited mutations in the $\beta$-globin gene complex, resulting a total absence or severe decrease in the production of $\beta$-globin chains $[8,9]$. The lack of $\beta$-globin chain production leads to the accumulations and precipitations of free intracellular $\alpha$-globin chains, which may consequently result in premature hemolysis of red blood cells and apoptosis of erythroid precursor $[8,10,11]$. Ineffective erythropoiesis has also been known to be related to inefficient iron utilization [12]. Therefore, the combining effects of ineffective erythropoiesis, hemolysis, and hypersplenism are the main culprit of severe anemia in $\beta$-thalassemia patients [5].

SCD is an inheritable autosomal recessive genetic blood disorder. It is characterized by the abnormal appearance of the red blood cells which are rigid and sickled. SCD is attributed to a point mutation at the coding sequence of the $\beta$-globin gene which causes the substitution of glutamate by valine in the glutamic acid at the sixth position of $\beta$-globin protein, and thus forming a sickle hemoglobin ( $\mathrm{HbS}, \alpha_{2} \beta_{2}^{\mathrm{S}}$ ) when incorporating into a hemoglobin tetramer $[13,14]$. 
HbS will polymerize inside the red blood cells under hypoxic condition, resulting in the alternation of the shape of red blood cells as well as their function.

Currently, the clinical manifestation in $\beta$ hemoglobinopathies is blood transfusion and gene transfer therapy. However, long-term transfusion therapy may cause iron overload in patients from the gradual breakdown of transfused blood which may eventually result in cardiac failure and/or even death [5]. Though the advance in iron chelation can help to remove excess iron in patients, the survival rate is greatly dependent on the iron chelation regimens [15]. Allogeneic hematopoietic stem cell transplantation (HSCT) is one of the gene transfer therapies aimed at the underlying molecular causes of SCD and $\beta$-hemoglobinopathies. Several hundred SCD and thalassemia patients have successfully experienced HSCT with promising results $[16,17]$. Nevertheless, there is a great likelihood that HSCT will be limited to a small proportion of hemoglobinopathy patients as evidence has shown merely younger patients and those who have not developed significant disease complications have gained the best results in HSCT [18]. Also, most successful transplantations have to utilize stem cells from matched sibling donors making HSCT a challenging therapy for some patients [16]. Therefore, HSCT may not be applicable to many current patients. Transferring of $\gamma$ - or $\beta$-hematopoietic stem cells of patients can be another therapy option for $\beta$-thalassemia patients [5]. It has taken a long period of time to have the clinical gene transfer protocol being approved since the transduction of human hematopoietic stem cells and gene expression must reach certain efficiency and high level [19]. Despite the fact that this approach has successfully passed its initial human trial, previous studies reported the issues regarding low autoploidy recombination [20], insertional mutagenesis, and effect of inserted vectors on the expression of nearby genes could possibly limit the application $[21,22]$.

Apart from gene therapy, fetal hemoglobin reactivation by chemical agents appears promising enough to develop into effective interventions to cure human $\beta$ hemoglobinopathies. Previous studies have revealed that homozygous $\beta$-thalassemia patients will not suffer severe anemia until fetal $\gamma$-globin genes are silenced and that patients carrying hereditary persistence of fetal hemoglobin (HPFH), meaning fetal hemoglobin ( $\mathrm{HbF}$ ) is abnormally persisted at high level in adults, will only suffer mild anemia $[8,13,23-27]$. More evidences also supported that HPFH can improve the severity of both $\beta$-thalassemia and SCD [1]. Therefore, it have been suggested that increasing the synthesis of fetal hemoglobin $(\mathrm{HbF})$ by reactivating fetal $\gamma$-globin gene can be a potential therapy in patients suffering $\beta$-thalassemia or SCD. It is expected that the pharmacological induction of $\mathrm{HbF}$ can correct the globin chain imbalance in $\beta$-thalassemia patients, while inhibit HbS polymerization in SCD patients [28-32].

In recent years, much effort has been made to identify the naturally occurring inducers and drug treatments which can increase the synthesis of $\mathrm{HbF}$ and promote the expression of fetal $\gamma$-globin gene. Some chemotherapeutic agents, for example, 5-azacytidine and hydroxyurea, (HU) have been reported due to their ability to enhance $\mathrm{HbF}$ production $[31,33,34]$. Yet, most of these currently identified HbFinducing agents exhibit low efficacy and specificity, myelotoxicity, and carcinogenesis as well as modest responses to treatment which greatly limit their usefulness in the clinical practice $[5,35,36]$. Owing to this, (i) discovering novel screening platform for identifying potential inducers with high efficiency and accuracy and (ii) identifying new HbFinducing agents from the natural world with the combination of efficacy, safety, and ease of use will be high on the agenda $[5]$.

\section{In Vivo and In Vitro Screening Platforms}

With the aim of determining the therapeutic potency of the novel inducing compounds and studying the underlying regulatory mechanism of the embryonic and fetal human globin genes expression, various in vitro and in vivo screening platforms have been widely utilized. For in vitro models, there are six human cell lines carrying an embryonic-HbF phenotype; they are K562 human chronic myelogenous leukemia cells, M-TAT, NSMeg, OCIM1, OCMI2, and AS-E2, while $\mathrm{K} 562$ cell line is one of the most well-known and widely used screening platforms for $\mathrm{HbF}$ inducers $[13,30]$. Another seven human cell lines which are capable of synthesizing both $\gamma$ and $\beta$-globin chains are JK-1, KMOE-2, KU812, LAMA-84, TF-1, TN922, and AP217; yet, KU812 cell line is comparatively unique and useful from the others as it can undergo a spontaneous differentiation which can be observed $[30,37-$ 39]. Moreover, human bone marrow CD34+ hematopoietic progenitors drawn from $\beta$-thalassemia patients and primary erythroid progenitors stem cells (EPSCs) obtained from peripheral blood are also great in vitro models to study the effect of different HbF-inducing agents $[1,13]$.

Back to the 1980s, baboons, a nonhuman primate model, have already been used for the study of fetal and adult hemoglobin synthesis during fetal development [40, 41]. There was an influential research conducted by De Simone and colleagues that the adult baboon has been shown to respond to erythropoietic stress with the reverse hemoglobin switch during which an increase in the number of $\mathrm{HbF}$ containing erythrocytes ( $\mathrm{F}$ cells) and an increase in $\mathrm{HbF}$ synthesis can be observed in adult baboon [40, 42, 43]. However, this animal model is expensive to purchase, feed, and maintain in conditions appropriate to modern animal husbandry. In order to understand the influence of HbF synthesis and its induction mechanism, till the 90s, researchers have successfully discovered that transgenic mice carrying human A $\gamma$-globin gene, which can act as a new in vivo model for screening novel pharmaceutical compounds for $\mathrm{HbF}$ induction in the adult $[44,45]$.

\section{Overviews on HbF Inducers}

Up to date, researchers have discovered numerous $\mathrm{HbF}$ inducing agents. These inducers can be categorized into several classes based on their mechanisms of action [13, 46] as listed in Table 1. Some of them are classified as 
TABLE 1: Classification of $\mathrm{HbF}$ inducers.

\begin{tabular}{lll}
\hline $\begin{array}{l}\text { Category } \\
\begin{array}{l}\text { Chemotherapeutic agents (ribonucleotide } \\
\text { reductase inhibitors) }\end{array}\end{array}$ & Examples of Inducers & Mechanism of action \\
\hline $\begin{array}{l}\text { Chemotherapeutic agents (DNA } \\
\text { methyltransferase inhibitors) }\end{array}$ & 5-Azacytidine, decitabine and citarabine & Inhibition of DNA analysis [13, 47] \\
\hline $\begin{array}{l}\text { Short chain fatty acids and derivatives } \\
\text { (histone deacetylase inhibitors) }\end{array}$ & $\begin{array}{l}\text { Butyrates, tricostatin, apicidine, and } \\
\text { scriptaid }\end{array}$ & $\begin{array}{l}\text { Inhibition of histone deacetylase (HDAC) activity } \\
\text { (applicable to some SCFAs only) [47, 56-65] }\end{array}$ \\
\hline $\begin{array}{l}\text { DNA binding agents } \\
\text { tallimustine and analogues, and angelicin }\end{array}$ & DNA-binding activity [5, 50] \\
\hline $\begin{array}{l}\text { mTOR inhibitors } \\
\text { Immunomodulatory drugs }\end{array}$ & $\begin{array}{l}\text { Thalidomide, revlimid, and } \\
\text { Pomalidomide }\end{array}$ & \begin{tabular}{l} 
FRAP-mTOR signal transduction targeting [49] \\
\hline Histone acetylation at $\gamma$-globin gene promoter \\
[5, 66]
\end{tabular} \\
\hline Eytokines & $\begin{array}{l}\text { Erythropoietin (EPO), stem cell factor } \\
\text { and TGF- } \beta\end{array}$ & $\begin{array}{l}\text { Increase in the frequency of erythroid progenitors } \\
\text { programmed to hemoglobin F } \\
{[5,47,52,53,67,68]}\end{array}$ \\
\hline
\end{tabular}

chemotherapeutic agents, for example, hydroxyurea (HU), 5azacytidine (5-Aza), decitabine, and citarabine. HU is also known as a ribonucleotide reductase inhibitor due to its ability of inhibiting DNA analysis, while 5-Aza, decitabine and citarabine are DNA methyltransferase inhibitors who responsible for the hypomethylation of DNA $[8,13]$. Several short-chain fatty acids (SCFAs) specifically stimulate transcription in the $\gamma$-globin gene promoter through histone deacetylase HDAC inhibition, resulting in global histone hyperacetylation $[5,47]$. In contrast, some studies argue that globin histone hyperacetylation induced is not the primary mechanism of SCFA [5]; yet, HDAC inhibitors are often potent $\gamma$-globin inducers $[47,48]$. Rapamycin belongs to the family of mTOR inhibitors. In erythroid precursor cells, rapamycin preferentially induce $\gamma$-globin mRNA accumulation, while being only minor for $\beta$-globin and none for $\alpha$ globin mRNAs [49]. As its HbF-inducing effect is not related to cytotoxicity and cell growth inhibition, scientists are very interested in further studying if the enhancement of $\gamma$-globin mRNA medicated by rapamycin is associated with $\mathrm{XmnI}$ polymorphism [49]. There are studies showing that K562 cells treated with DNA-binding agents, such as mithramycin, have led to erythroid differentiation and sharp enhancement of $\gamma$ globin mRNA level [50]. Through PCR arrested experiments, it is found that these DNA-binding drugs were capable of interacting with $\gamma$-globin promoter of human genomic DNA [50]. In recent years, researches have been done on immunomodulatory drugs, such as thalidomide, revlimid, and pomalidomide. Their exhibited HbF-inducing activity has been revealed in K562 or primary human erythroid cultures. Further study has demonstrated their activity is associated with the increase in histone acetylation at $\gamma$-globin gene promoter [51]. Erythropoietin (EPO) is a cytokine that have been shown to induce $\mathrm{HbF}$ production during in vitro differentiation of primary human cells in several trials [47, 52-55]. It also stimulates red blood cells production, prolongs the survival of erythroid cells, and decreases the incident of programmed cell death [47].

\section{Natural Remedies as HbF Inducer}

In recent years, scientists have conducted numerous studies in order to identify the natural remedies that could be possibly applied in treating $\beta$-hemoglobinopathies, including SCD and $\beta$-thalassemia, summarized in Table 2 . The extract of Aegle Marmelos containing bergatene was found to be responsible for the activation of erythroid differentiation and $\mathrm{HbF}$ induction in human leukemic K562 cells [31, 69]. Citropten and bergatene are the active ingredients in bergamot juice. They are powerful inducers of erythroid differentiation, $\gamma$-globin gene expression and $\mathrm{HbF}$ synthesis in human erythroid cells. Thus, it is known as a potential therapeutic approach for both $\beta$-thalassemia and sickle cell anemia [69]. In addition, Nicosan (formerly known as Niprisan), an ethanol/water extract from Nigeria indigenous plants, has successfully demonstrated a significant anti-sickling effects in vitro as well as in vivo $[70,71]$.

Angelicin can be found in the fruit of Angelica arcangelica. There is evidence demonstrating that angelicin is a powerful inducer of erythroid differentiation, enhancement of the $\mathrm{HbF}$ synthesis in erythroid progenitors and $\gamma$-globin mRNA accumulation of human leukemia K562 cells [8,73]. Red wine, especially the skin of grapes, contains resveratrol which mimics the HbF-inducing activity of $\mathrm{HU}$ [8]. Its function in increasing the $\gamma$-globin mRNA in human erythroid precursors has been confirmed [8]. Since $\beta$-thalassemia cells exhibit a high level of oxidative stress, which eventually shorten the survival of erythroid cells in $\beta$-thalassemia patients, resveratrol which exhibits both antioxidant activity and $\mathrm{HbF}$ inducing property can become a very promising $\mathrm{HbF}$ inducer from the natural world [74].

Rapamycin is isolated from Streptomyces hygroscopicus, a bacterial species being found in the soil of Easter Island. It has the ability to increase $\mathrm{HbF}$ production in cultures of erythroid precursors from $\beta$-thalassemia patients without cytotoxicity or growth-inhibitory effect $[8,13]$. Apart from this, in Streptomyces species, mithramycin can be easily 
TABLE 2: Natural remedies as HbF inducer.

\begin{tabular}{lll}
\hline Inducer & Source & Biological effects \\
\hline Bergaptene & Aegle marmelos & $\begin{array}{l}\text { Erythroid differentiation of K562 cells, HbF induction } \\
{[31,72]}\end{array}$ \\
\hline Angelicin & Angelica arcangelica & $\begin{array}{l}\text { Erythroid differentiation, } \\
\text { HbF induction [8,73] }\end{array}$ \\
\hline Resveratrol & Red wine, grape skin, and darakchasava & HbF induction [8,74] \\
\hline Citropten and bergapten & Bergamot orange & Erythroid differentiation and HbF production [69] \\
\hline Rapamycin & Streptomyces hygroscopicus & HbF induction [8, 13] \\
\hline Mithramycin & Streptomyces species & HbF production [75] \\
\hline YiSui ShengXue Granule & & $\begin{array}{l}\text { Erythroid survival, proliferation, and terminal } \\
\text { differentiation of K562 cells and HbF production [76] }\end{array}$ \\
\hline Cucurbitacin D & $\begin{array}{l}\text { Ethanol Extract of Fructus trichosanthis, } \\
\text { which is the fruit of Trichosanthes kirilowii }\end{array}$ & $\begin{array}{l}\text { HbF production and Erythroid differentiation of K562 } \\
\text { cell, 31] }\end{array}$ \\
\hline $\begin{array}{l}\text { Niprisan/Nix-0699/Nicosan } \\
\text { Terminalia catappa distilled } \\
\text { water active fraction (TCDWF) }\end{array}$ & $\begin{array}{l}\text { A ethanol/water extract developed in } \\
\text { Nigeria from indigenous plants }\end{array}$ & Anti-sickling effect [31, 70, 71] \\
\hline
\end{tabular}

isolated. It is a DNA-binding drug which has the potential to induce $\gamma$-globin mRNA accumulation and $\mathrm{HbF}$ production in erythroid cells from healthy human subjects as well as $\beta$ thalassemia patients [75].

Recently, it is reported that an Indian almond, called Terminalia catappa, has long been used as a traditional herbal treatment for SCA in Nigeria [78]. Aimola et al. has then demonstrated Terminalia catappa distilled water active fraction (TCDWF) from Terminalia catappa leaves exhibit a stimulatory effect on the $\mathrm{HbF}$ production in primary erythroid prohenitor stem cells (EPSCs) [77]. Terminalia catappa consists of flavonoids, alkaloids, and anthraquinones. Also, through gas chromatography-mass spectrometry (GCMS), it is shown that a group of highly related long-chain fatty acids, for example, hexadecanoic acid, 10-octadecenoic acid, and octadecenoic acid, are present in the TCDWF [77]. Yet, further investigation is required in order to confirm the biological activities of these active compounds present in the TCDWF.

For the Chinese herbal medicine, YiSui ShengXue Granule (YSSXG), a complex prescription made up of 11 different kinds of Chinese herbal medicines, has shown to be effective in enhancing the $\mathrm{HbF}$ expression and inhibiting ineffective hematopoiesis $[76,79]$. Current research has further confirmed this complex prescription has the ability to increase $\gamma$-globin gene expression and alter the expression of genes that involved in the survival, proliferation, and terminal differentiation of erythroid cells [76]. Recently, some researchers found that cucurbitacin $\mathrm{D}(\mathrm{CuD})$ in a Chinese medicinal herb, called Fructus trichosanthis (FT), exhibits a higher potency in $\mathrm{HbF}$ induction compared with hydroxyurea since there is evidence showed $\mathrm{CuD}$ results in a higher fetal cell percentage and greater $\mathrm{HbF}$ content in K562 cells with much lower cytotoxicity [1].

\section{Mechanism of Actions of HbF Induction}

Up to date, more than $70 \mathrm{HbF}$-inducing agents have been described [5]. Scientists have started to put effort on appreciating their underlying molecular mechanisms as well as verifying their target molecules.

5.1. 338 MAPK Pathway. The first piece of evidence regarding the cell signaling of the $\mathrm{HbF}$ induction has suggested that, in K562 cells, butyrate induces erythroid differentiation and hemoglobin production through 38 MAPK pathway $[1,80]$. Several years later, another group of scientists has interestingly revealed that, without drug treatment, the $\gamma$-globin mRNA level is increased sufficiently solely by overexpressing MAPKK3 and MAPKK 6 which are the direct upstream activators of p38 in K562 cells [81]. According to Mabaera et al., p38 MAPK signaling pathway is critical for the upregulation of the production of $\mathrm{HbF}$ [5]. Different environmental stresses could activate the p38 MAPK signal pathway which will subsequently cause apoptosis, cell growth and erythroid differentiation. Various studies have also revealed the effect of numerous HbF-inducing agents, such as butyrate [82], apicidin [83], and trichostatin A [84], are associated with p38 MAPK signaling pathway. Therefore, they both indicated p38 MAPK pathway plays a vital role in promoting $\gamma$-globin gene expression.

During the past few years, researchers come up with different mechanistic models of $\mathrm{HbF}$ induction while most of the models are generally based on what are thought to be the primary actions of $\mathrm{HbF}$-inducing agents, for instance, global DNA hypomethylation induced by DNA methyltransferase inhibitors (DNMT inhibitors) or global histone hyperacetylation induced by histone deacetylase inhibitors (HDAC inhibitors), including SCFA derivatives. However, 
when we come across with the recent key experimental findings, including the fact that 5 -Aza can promote $\mathrm{HbF}$ production without DNA hypomethylation, that $\gamma$-globin promoter hypomethylation is inadequate to stimulate gene expression, and that the ability of HDAC inhibitors to induce $\mathrm{HbF}$ is regardless of the potency of HDAC inhibitions, some of these proposed mechanistic models are no longer capable to explain those results. Therefore, it is of essence to propose a new model of $\mathrm{HbF}$ induction which is valid to most HbFinducing agents and can adequately account for the recent experimental results [5].

Mabaera et al., through integrating recent results of cellsignaling experiments with the stress erythropoiesis model, have proposed a new model called the cell stress signaling model [5]. They suggested that the key effect of most HbFinducing agents is to activate the cell stress signaling pathways during adult erythropoiesis which subsequently lead to $\gamma$ globin gene expression and $\mathrm{HbF}$ production. It is found that certain HbF-inducing agents, such as HU, Butyrate (SCFA), Thalidomide (IMiD), Trichostatin A (HDAC Inhibitor), and anisomycin, can activate the corresponding cell stress responses, including nitric oxide, oxidative stress (ROS), osmotic shock, and protein synthesis inhibition. These cell stress responses will eventually activate the downstream p38 MAPK signaling pathway, including downstream kinases and transcription factors, and thus result in $\gamma$-globin gene expression and $\mathrm{HbF}$ production. Besides $\mathrm{p} 38$ MAPK signaling pathway, the potential of cAMP signaling pathway in $\mathrm{HbF}$ production has also been mentioned in the cell stress signaling model. There are findings suggested that in primary erythroid cell cultures, cAMP response element binding protein (CREB) is activated by cAMP-activated protein kinase A instead of p38 MAPK pathway. The phosphorylated CREB will then activate the downstream transcription factors and eventually lead to $\gamma$-globin gene expression. Therefore, not only is the cell stress signaling model applicable to most of the HbF-inducing agents but also is able to explain the key findings of some of the previous experiments [5].

5.2. Roles of ERK and JNK. In the previous studies, researchers have found out that stimulating ERK signaling pathway leads to megakaryocytic differentiation; contrastingly, suppressing ERK signaling pathway results in the enhancement of the erythroid phenotype as well as the $\gamma$ globin mRNA expression [83]. Moreover, the evidence that ERK inhibitor U0126 has the ability to stimulate $\gamma$-globin gene expression and $\mathrm{HbF}$ production in human erythroid progenitor cells suggested the inhibition of ERK can possibly lead to the promotion of HbF production [84]. The involvement of JNK in erythroid differentiation still remained debatable [76, 85-87]. It is reported that pretreatment with HU in K562 cells has led to a significant inhibition of JNK [85]. Moreover, short chain fatty acid derivatives (SCFAD), such as butyrate and valproate, did not result in JNK phosphorylation; thus, there was not any significant changes on JNK pathway in K562 cells [76, 87]. Nevertheless, in mouse erythroleukemia cells, experimental findings have suggested that activation of JNK is crucial for erythropoietin-induced erythroid differentiation $[86,88]$. As a result, whether JNK plays a significant role in $\mathrm{HbF}$ induction still remains to be investigated in the future.

5.3. Trans-Acting Factor and Cis-Acting Element of the Globin Gene. The potential of reactivating fetal hemoglobin via manipulating the gene transcription of $\beta$ - or $\gamma$-globin has been gained much attention recently. There is escalated number of publications regarding the genetic regulatory mechanism of developmental stage-specific expression of $\beta$-globin genes. The mechanisms accounting for switching globin-genes expression during the development are highly regulated by cis-acting elements and trans-acting factors which include the locus control region (LCR) [85, 86]. Previous studies have also revealed that LCR has an important of enhancing globin-gene switching potently [86]. Understanding the fetal-to-adult hemoglobin switching is believed to have a clinical relevance of developing novel approaches of reversal of fetal hemoglobin production from adult hemoglobin in patients [87]. Several researchers have applied the knowledge of the regulatory mechanisms of globin-genes expression to design an artificial zinc finger DNA-binding domain (ZF-DBD) with the aim of manipulating the expression patterns of globin-genes [85, 87]. Therefore, techniques involving small molecule inhibitors or genetic knockdown can be potential applications to reactivate the fetal hemoglobin in the future [87].

5.4. Posttranslational Regulation of $\gamma$-Globin Gene Expression. Interestingly, besides the discovery of the upstream signaling pathway of activating the $\gamma$-globin gene expression, there are findings supporting the fact that posttranscriptional regulation also involves in regulating the $\gamma$-globin gene expression in response to different stimuli $[89,90]$. Weinberg et al. revealed that instead of acting on the transcription rate of $\gamma$-globin gene in patients, butyrate has the ability to enhance the efficiency of translation of $\gamma$-globin mRNA [56]. Moreover, there is evidence proving that the key effect of GTP and doxorubicin derivatives is the elevation of the amount of $\gamma$-globin in patients, at least partially, by enhancing the stability of $\gamma$-globin mRNA [91, 92]. Liu et al. also suggested that, similar to GTP and doxorubicin derivatives, $\mathrm{CuD}$ can therapeutically induce the production of $\mathrm{HbF}$ due to its ability of increasing $\gamma$-globin mRNA stability [1]. They have showed even though the change in the half-life of $\gamma$-globin mRNA is small, it leads to remarkable changes in the total amount of stable $\gamma$-globin mRNA and consequently the amount of functional $\gamma$-globin present in the cell. Therefore, the control of $\gamma$-globin mRNA stability can be known as a significant regulatory mechanism of $\gamma$-globin gene expression [93].

\section{Current Therapeutic Obstacles}

In $\beta$-thalassemia, due to the precipitation of excess $\alpha$-globin chains, rapid cellular apoptosis of early erythroblasts and red blood cell membrane damage are well characterized [94-96]. 5-Azacytidine, hydroxyurea, myleran, and butyrate had long been applied in clinics for $\beta$-thalassemia treatment with the 
aim of stimulating $\mathrm{HbF}$ production [97-100]. Despite the ability of inducing the production of $\mathrm{HbF}$ in $\beta$-thalassemia, a large portion of identified $\mathrm{HbF}$-inducing agents, such as 5azacytidine and hydroxyurea, are chemotherapeutic agents which inhibit cell proliferation and cause cell growth arrest [47]. Further, due to their cytotoxic nature, the dose limiting myelotoxicity and potential carcinogenicity have always led to concerns [76]. Therefore, in order to correct the pathophysiology of $\beta$-thalassemia, it is of essence to improve the underlying erythroid cell survival and proliferation, with the intention that HbF-inducing agents can exert their effect on stimulating the fetal globin expression prior to the activation of irreversible programmed cell death pathway [47]. Owing to this issue, Perrine et al. (2002) have conducted a pilot study revealing the combination of butyrate and rhu-erythropoietin (EPO), the hematopoietic growth factor that stimulates erythroid proliferation, decreases apoptosis, and prolongs erythroid cell survival and differentiation, has addictive effects in inducing hematologic responses in any $\beta$-thalassemia patients [101]. This result further suggested that definitive treatment to correct $\beta$-thalassemia will likely require more than one type of therapeutic regimen; in other words, hematopoietic growth factor, such as exogenous EPO will be required for $\beta$-thalassemia patients in order to respond optimally to any HbF-inducing agent [47].

Hydroxyurea (HU) was first approved by the Food and Drug Administration (FDA) for the treatment of sickle cell disease (SCD) in 1996 [102]; yet, HU only increases $\mathrm{HbF}$ production in approximately half of SCD patients [103] and is even less effective in enhancing the $\mathrm{HbF}$ level for $\beta$ thalassemia patients [104-106]. Additionally, there is a recent clinical trial conducted to assess the therapeutic potential of HQK-1001, an oral butyrate derivative 2,2-dimethylbutyrate sodium salt to treat $\beta$-thalassemia patients [107]. Although results revealed HQK-1001 exhibits a stimulatory effect on $\mathrm{HbF}$ production and $\gamma$-globin gene expression, further study is needed to find out if the surge of $\mathrm{HbF}$ production is sufficient to alleviate the complications of $\beta$-thalassemia including anaemia, chronic haemolysis, and so forth [107]. Nevertheless, up to date, there is no such pharmacological agent(s) has been officially approved by FDA for treating patients with $\beta$-thalassemia [102]. The underlying reason of this is that for pharmacological $\mathrm{HbF}$ induction therapy in patients with thalassemia major, it requires the production of $\gamma$-globin chains (plus $\beta$-globin chains in thalassemia major) reaches $50 \%$ of the production of $\alpha$-globin chains in order to result in optimal therapeutic correction of the anemia in patients with $\beta$-thalassemia; while for that in patients with SCD, it only requires the production of $\mathrm{HbF}$ reaches $20-$ $30 \%$ of total circulating hemoglobin for sufficient prevention of sickling effect in SCD [102]. Therefore, it is necessary to identify novel pharmacological $\mathrm{HbF}$ inducer or alternate therapeutic approaches which can effectively enhance the $\mathrm{HbF}$ production to the optimal level and sufficiently reduce the chain imbalance in homozygous $\beta$-thalassemia [102].

In recent years, Mabaera et al. (2008) have proposed p38 MAPK cell stress signaling pathway and other stressrelated pathways may be the keys to understanding $\mathrm{HbF}$ induction, owing to the fact that most HbF-inducing agents are, as mentioned before, cytotoxic and many activate the p38 MAPK cell stress signaling pathway. This stress signaling model predicts a variety of diverse $\mathrm{HbF}$-inducing compounds and stimuli will activate cell stress signaling pathway which will then activate similar response genes, such as the $\gamma$-globin genes [5]. It is supported by several observation and evidence, for example, the stimulation of $\gamma$-globin gene expression and $\mathrm{HbF}$ production in human primary erythroid cells by 5 azacytidine is closely related to p38 MAPK phosphorylation and this stimulation is inhibited when treated with p38 MAPK inhibitor SB203580 [5]. On the other hand, based on the stress signaling model, Mabaera and colleagues (2008) have also made some predictions which require further investigation, for example, the members of stress signaling pathways, ranging from the sensors of cellular stress to the activated transcription factors that bind to the $\gamma$-globin gene promoters, are needed for activating the $\gamma$-globin gene expression as well as $\mathrm{HbF}$ production [5].

Nevertheless, concerns have been raised about the possibility of triggering rapid cellular apoptosis in erythroid cells and consequently leading to low blood count when patients, especially those with thalassemia, are receiving chemotherapeutic agents including 5-azacytidine, decitabine, HU and butyrate [5]. Comparing with SCD patients, $\beta$ thalassemia patients are more susceptible to chemotherapeutic agents because treating with chemotherapeutic agents may further encourage rapid cellular apoptosis which has already been well-characterized in $\beta$-thalassemia patients even they are not exposed to the agents. Also, as mentioned before, accelerated cellular apoptosis of erythroid progenitors in $\beta$-thalassemia is a significant barrier to definitive therapy because there is a high possibility that the programmed cell death will be established earlier before HbF-inducing agents act its beneficial effect on the globin chain balance in cells [47]. Consequently, chemotherapeutic agents, such as $\mathrm{HU}$, butyrate and 5-azacytidine, may not be the best $\mathrm{HbF}$ inducer for $\beta$-thalassemia due to the fact that the $\mathrm{HbF}$ inducing property of those agents are largely dependent on the activation of cell stress signaling pathway. In contrast, those chemotherapeutic agents may have beneficial effect on activating $\gamma$-globin gene expression and $\mathrm{HbF}$ production in SCD; yet, the dose of inducing agents must be strictly monitored in order to ensure it is high enough to activate stress signaling pathway but not too high to trigger cell-cycle arrest or apoptosis in hematopoietic precursor cells that will result in dangerously low blood counts.

\section{Future Perspectives}

In light of the lack of promising $\mathrm{HbF}$-inducing agents for $\beta$-thalassemia treatment, up to now, different research groups have paid lots of effort on identifying the existing or novel natural Chinese herbal medicines which have the possibility to effectively induce $\mathrm{HbF}$ synthesis without any apparent growth-inhibitory effects. YiSui ShenXu Granule (YSSXG), a complex prescription consisting of 11 Chinese herbal medicines, had been used for treating $\beta$-thalassemia for more than over 20 years [76, 79]. Recently, effort has been put on investigating the efficacy and safety of YSSXG 
by a randomized single-blinded trial. Result has demonstrated it has obvious clinical efficacy, while hepatauxe and splenomegaly were relieved and no adverse reaction was observed [108]. The underlying mechanism for the effect of YSSXG is possibly by activating the expression of $\gamma$-globin gene and increase $\mathrm{HbF}$ production in order to compensate for the functional deficiency of $\beta$-globin gene [20]. Zhang and $\mathrm{Wu}$ have found out that stimulating the gene expression of $\gamma$-globin, EpoR, Spi, and FKLF, while hindering the gene expression of Ckit, GATA1, and GATA2, could promote the $\gamma$ globin gene expression and alter the expression of gene which is responsible for the regulation of $\gamma$-globin gene expression and the expression of other genes that are participated in the survival, proliferation, and terminal differentiation of erythroid cells [76].

Apart from that, Li et al. (2011) have presented the first piece of evidence on the HbF-inducing property of ethanol extract of Fructus trichosanthis (FT), one of the most frequently used Chinese herbal medicine [31]. Their study has demonstrated FT has the ability to enhance the $\gamma$-globin gene expression as well as $\mathrm{HbF}$ synthesis through activating p38 MAPK and inhibiting ERK signaling pathway [31]. Despite the promising result shown, acute and chronic toxicity test in vivo is strongly required in the future in order to ensure the ethanol extract of FT is safe for clinical use on human. Also, the efficacy of the extract should be examined in clinical evaluation before actual clinical practice [31]. During the same year, another group of researchers have identified Cucurbitacin D (CuD), a chemical inducing agent that can be found in Fructus trichosanthis, is a novel therapeutic agent for treating $\beta$-thalassemia [1]. There are evidences suggesting that $\mathrm{CuD}$ could act as a good HbFinducing agent for $\beta$-thalassemia patient comparing with $\mathrm{HU}$ since $\mathrm{CuD}$ exhibits a higher amplitude and rapidity in enhancing the HbF production than HU does in K562 cells, and, unlike $\mathrm{HU}, \mathrm{CuD}$ does not show any growth-inhibitory effect even when it is at its optimal activity [1]. Taken all together, natural herbal medicines, which exhibit a higher potency in $\mathrm{HbF}$ induction compared with chemotherapeutic agents and have much lower cytotoxicity, will definitely be the novel therapeutic candidates for $\beta$-thalassemia by targeting the activation of $\gamma$-globin gene expression; yet, some of the candidates are still required further investigation on their safety and efficacy [1].

\section{Conclusion}

Chemotherapeutic agents, such as 5-azacytidine, hydroxyurea, myleran, and butyrate, had long been used for $\beta$ thalassemia treatment by stimulating $\mathrm{HbF}$ synthesis; yet, cytotoxicity, growth-inhibitory effect, fear of long-term carcinogenesis, and only modest $\mathrm{HbF}$-inducing activity have limited the clinical usage of these agents in $\beta$-thalassemia and SCD treatment. Also, through understanding the pathology of $\beta$-thalassemia, it is revealed that most of the identified $\mathrm{HbF}$-inducing agents have limitation on treating $\beta$ thalassemia. It is because the rapid cellular apoptosis of erythroid progenitors in $\beta$-thalassemia causes a significant obstacle that overstimulating the cell stress signaling pathway by the HbF inducer may possibly lead to irreversible cellular apoptosis before $\gamma$-globin gene expression and $\mathrm{HbF}$ synthesis can be stimulated. With the advancement of biotechnologies, increasing number of studies will be done to explore and optimize new interventions and nature remedies to reactivate $\mathrm{HbF}$ synthesis for $\beta$-thalassemia patients. In the future, it is expected that increasing number of $\mathrm{HbF}$ inducing agents could be found from natural remedies and folk medicines all over the world. In this context, further studies are required with the aim of exploring more natural herbal medicines as well as studying the efficacy and safety of from the laboratory to clinical use for the individuals with $\beta$-hemoglobinopathies.

\section{Conflict of Interests}

The authors declare that they have no conflict of interests with the commercial identities mentioned in this work. This review was solely done for scientific research reasons.

\section{Acknowledgments}

This study was supported by the Ming Lai Foundation, The International Association of Lions Clubs District 303, and Hong Kong \& Macau Tam Wah Ching Chinese Medicine Resource Centre.

\section{References}

[1] K. Liu, H. Xing, S. Zhang, S. M. Liu, and M. C. Fung, "Cucurbitacin D induces fetal hemoglobin synthesis in K562 cells and human hematopoietic progenitors through activation of p38 pathway and stabilization of the $\gamma$-globin mRNA," Blood Cells, Molecules, and Diseases, vol. 45, no. 4, pp. 269-275, 2010.

[2] B. E. Glader and K. A. Look, "Hematologic disorders in children from Southeast Asia," Pediatric Clinics of North America, vol. 43, no. 3, pp. 665-681, 1996.

[3] A. H. Khelil, S. Denden, N. Leban et al., "Hemoglobinopathies in North Africa: a review," Hemoglobin, vol. 34, no. 1, pp. 1-23, 2010.

[4] C. Kattamis and A. C. Kattamis, "Genotypes and phenotypes of beta-thalassemia in Mediterranean populations," Journal of Pediatric Hematology/Oncology, vol. 14, no. 3, pp. 7-9, 1997.

[5] R. Mabaera, R. J. West, S. J. Conine et al., "A cell stress signaling model of fetal hemoglobin induction: what doesn't kill red blood cells may make them stronger," Experimental Hematology, vol. 36, no. 9, pp. 1057-1072, 2008.

[6] R. L. Nagel and E. F. Roth Jr., "Malaria and red cell genetic defects," Blood, vol. 74, no. 4, pp. 1213-1221, 1989.

[7] M. Aidoo, D. J. Terlouw, M. S. Kolczak et al., "Protective effects of the sickle cell gene against malaria morbidity and mortality," The Lancet, vol. 359, no. 9314, pp. 1311-1312, 2002.

[8] A. El-Beshlawy, M. Hamdy, and M. El Ghamrawy, "Fetal globin induction in $\beta$ thalassemia," Hemoglobin, vol. 33, no. 1, pp. S197S203, 2009.

[9] D. J. Weatherall and J. B. Clegg, "The thalassemia syndromes," in The Thalassemia Syndromes, D. J. Weatherall and B. Clegg, Eds., pp. 287-356, Blackwell Science, 4th edition, 2001.

[10] D. R. Higgs, S. L. Thein, and W. G. Woods, "The physiology of the thalassemia," in The Thalassemia Syndromes, D. J. Weatherall 
and B. Clegg, Eds., pp. 265-284, Blackwell Science, 4th edition, 2001.

[11] S. L. Schrier, "Pathophysiology of thalassemia," Current Opinion in Hematology, vol. 9, no. 2, pp. 123-126, 2002.

[12] S. Gardenghi, M. F. Marongiu, P. Ramos et al., "Ineffective erythropoiesis in $\beta$-thalassemia is characterized by increased iron absorption mediated by down-regulation of hepcidin and up-regulation of ferroportin," Blood, vol. 109, no. 11, pp. 50275035, 2007.

[13] N. Bianchi, C. Zuccato, I. Lampronti, M. Borgatti, and R. Gambari, "Fetal hemoglobin inducers from the natural world: a novel approach for identification of drugs for the treatment of $\beta$-thalassemia and Sickle-cell anemia," Evidence-based Complementary and Alternative Medicine, vol. 6, no. 2, pp. 141-151, 2009.

[14] A. Kutlar, "Sickle cell disease: a multigenic perspective of a single gene disorder," Hemoglobin, vol. 31, no. 2, pp. 209-224, 2007.

[15] T. E. Delea, J. Edelsberg, O. Sofrygin et al., "Consequences and costs of noncompliance with iron chelation therapy in patients with transfusion-dependent thalassemia: a literature review," Transfusion, vol. 47, no. 10, pp. 1919-1929, 2007.

[16] M. Bhatia and M. C. Walters, "Hematopoietic cell transplantation for thalassemia and sickle cell disease: Past, present and future," Bone Marrow Transplantation, vol. 41, no. 2, pp. 109-117, 2008.

[17] S. Shenoy, "Has stem cell transplantation come of age in the treatment of sickle cell disease?" Bone Marrow Transplantation, vol. 40, no. 9, pp. 813-821, 2007.

[18] M. C. Walters, M. Patience, W. Leisenring et al., "Barriers to bone marrow transplantation for sickle cell anemia," Biology of Blood and Marrow Transplantation, vol. 2, no. 2, pp. 100-104, 1996.

[19] M. Sadelain, "Recent advances in globin gene transfer for the treatment of beta-thalassemia and sickle cell anemia," Current Opinion in Hematology, vol. 13, no. 3, pp. 142-148, 2006.

[20] S. Fang, Z. Wu, X. Zhang et al., "Clinical observation on YiSuiShengXueGranule on treating 156 patients with $\beta$-thalassemia major and the molecular mechanism study," Biological and Pharmaceutical Bulletin, vol. 30, no. 11, pp. 2084-2087, 2007.

[21] C. E. Dunbar, “The yin and yang of stem cell gene therapy: insights into hematopoiesis, leukemogenesis, and gene therapy safety," Hematology, pp. 460-465, 2007.

[22] P. W. Hargrove, S. Kepes, H. Hanawa et al., "Globin lentiviral vector insertions can perturb the expression of endogenous genes in $\beta$-thalassemic hematopoietic cells," Molecular Therapy, vol. 16, no. 3, pp. 525-533, 2008.

[23] B. G. Forget, "Molecular basis of hereditary persistence of fetal hemoglobin," Annals of the New York Academy of Sciences, vol. 850, pp. 38-44, 1998.

[24] U. Bhardwaj and E. R. B. McCabe, "Multiplex-PCR assay for the deletions causing hereditary persistence of fetal hemoglobin," Molecular Diagnosis, vol. 9, no. 3, pp. 151-156, 2005.

[25] L. R. Liu, Z. W. Du, H. L. Zhao et al., "T to C substitution at -175 or -173 of the $\gamma$-globin promoter affects GATA- 1 and Oct1 binding in vitro differently but can independently reproduce the hereditary persistence of fetal hemoglobin phenotype in transgenic mice," The Journal of Biological Chemistry, vol. 280, no. 9, pp. 7452-7459, 2005.

[26] C. Garner, T. K. Dew, R. Sherwood, D. Rees, and S. L. Thein, "Heterocellular hereditary persistence of fetal haemoglobin affects the haematological parameters of $\beta$-thalassaemia trait," British Journal of Haematology, vol. 123, no. 2, pp. 353-358, 2003.

[27] E. Gallo, P. Massaro, R. Miniero, D. David, and C. Tarella, "The importance of the genetic picture and globin synthesis in determining the clinical and haematological features of thalassaemia intermedia," British Journal of Haematology, vol. 41, no. 2, pp. 211-221, 1979.

[28] S. A. Ali, "Milder variant of sickle-cell disease in Arabs in Kuwait associated with unusually high level of foetal haemoglobin," British Journal of Haematology, vol. 19, no. 5, pp. 613-619, 1970.

[29] W. G. Wood, J. B. Clegg, and D. J. Weatherall, "Hereditary persistence of fetal hemoglobin (HPFH) and $\delta \beta$ thalassemia," British Journal of Haematology, vol. 43, no. 4, pp. 509-520, 1979.

[30] S. Zein, W. Li, V. Ramakrishnan et al., "Identification of fetal hemoglobin-inducing agents using the human leukemia KU812 cell line," Experimental Biology and Medicine, vol. 235, no. 11, pp. 1385-1394, 2010.

[31] H. Li, C. H. Ko, S. Y. Tsang, P. C. Leung, M. C. Fung, and K. P. Fung, "The ethanol extract of Fructus trichosanthis promotes fetal hemoglobin production via p38 MAPK activation and Erk inactivation in K562 cells," Evidence-Based Complementary and Alternative Medicine, vol. 2011, Article ID 657056, 8 pages, 2011.

[32] N. F. Olivieri and D. J. Weatherall, "The therapeutic reactivation of fetal haemoglobin," Human Molecular Genetics, vol. 7, no. 10, pp. 1655-1658, 1998.

[33] Y. Watanapokasin, S. Chuncharunee, D. Sanmund et al., "In vivo and in vitro studies of fetal hemoglobin induction by hydroxyurea in $\beta$-thalassemia/hemoglobin E patients," Experimental Hematology, vol. 33, no. 12, pp. 1486-1492, 2005.

[34] P. Heller and J. DeSimone, "5-Azacytidine and fetal hemoglobin," The American Journal of Hematology, vol. 17, no. 4, pp. 439-447, 1984.

[35] J. J. Strouse, S. Lanzkron, M. C. Beach et al., "Hydroxyurea for sickle cell disease: a systematic review for efficacy and toxicity in children," Pediatrics, vol. 122, no. 6, pp. 1332-1342, 2008.

[36] M. L. Randi, E. Ruzzon, F. Tezza, G. Luzzatto, and F. Fabris, "Toxicity and side effects of hydroxyurea used for primary thrombocythemia," Platelets, vol. 16, no. 3-4, pp. 181-184, 2005.

[37] H. G. Drexler, Y. Matsuo, and R. A. F. MacLeod, "Malignant hematopoietic cell lines: in vitro models for the study of erythroleukemia," Leukemia Research, vol. 28, no. 12, pp. 1243$1251,2004$.

[38] J. L. Villeval, P. G. Pelicci, A. Tabilio et al., "Erythroid properties of K562 cells. Effect of hemin, butyrate and TPA induction," Experimental Cell Research, vol. 146, no. 2, pp. 428-435, 1983.

[39] R. Gambari, L. del Senno, R. Barbieri et al., "Human leukemia K-562 cells: induction of erythroid differentiation by 5 azacytidine," Cell Differentiation, vol. 14, no. 2, pp. 87-97, 1984.

[40] J. DeSimone, P. Heller, L. Hall, and D. Zwiers, "5-Azacytidine stimulates fetal hemoglobin synthesis in anemic baboons," Proceedings of the National Academy of Sciences of the United States of America, vol. 79, no. 14, pp. 4428-4431, 1982.

[41] J. de Simone and A. L. Mueller, "Fetal hemoglobin (HbF) synthesis in baboons, Papio cynocephalus. Analysis of fetal and adult hemoglobin synthesis during fetal development," Blood, vol. 53, no. 1, pp. 19-27, 1979.

[42] J. DeSimone, S. I. Biel, and P. Heller, "Stimulation of fetal hemoglobin synthesis in baboons by hemolysis and hypoxia," Proceedings of the National Academy of Sciences of the United States of America, vol. 75, no. 6, pp. 2937-2940, 1978. 
[43] P. E. Nute, P. Chen, and G. Stamatoyannopoulos, "Acceleration of F-cell production in response to experimentally induced anemia in adult baboons (Papio cynocephalus)," American Journal of Hematology, vol. 8, no. 2, pp. 157-168, 1980.

[44] P. Constantoulakis, B. Josephson, L. Mangahas et al., "Locus control region-A $\gamma$ transgenic mice: a new model for studying the induction of fetal hemoglobin in the adult," Blood, vol. 77, no. 6, pp. 1326-1333, 1991.

[45] B. S. Pace, H. L. Elford, and G. Stamatoyannopoulos, "Transgenic mouse model of pharmacologic induction of fetal hemoglobin: studies using a new ribonucleotide reductase inhibitor, Didox," American Journal of Hematology, vol. 45, no. 2, pp. 136-141, 1994.

[46] R. Gambari and E. Fibach, "Medicinal chemistry of fetal hemoglobin inducers for treatment of $\beta$-thalassemia," Current Medicinal Chemistry, vol. 14, no. 2, pp. 199-212, 2007.

[47] S. P. Perrine, S. A. Castaneda, M. S. Boosalis, G. L. White, B. M. Jones, and R. Bohacek, "Induction of fetal globin in $\beta$ thalassemia: cellular obstacles and molecular progress," Annals of the New York Academy of Sciences, vol. 1054, pp. 257-265, 2005.

[48] H. Cao, G. Stamatoyannopoulos, and M. Jung, "Induction of human $\gamma$ globin gene expression by histone deacetylase inhibitors," Blood, vol. 103, no. 2, pp. 701-709, 2004.

[49] E. Fibach, N. Bianchi, M. Borgatti et al., "Effects of rapamycin on accumulation of alpha-, beta- and gamma-globin mRNAs in erythroid precursor cells from beta-thalassaemia patients," European Journal of Haematology, vol. 77, no. 5, pp. 437-441, 2006.

[50] N. Bianchi, F. Osti, C. Rutigliano et al., "The DNA-binding drugs mithramycin and chromomycin are powerful inducers of erythroid differentiation of human K562 cells," British Journal of Haematology, vol. 104, no. 2, pp. 258-265, 1999.

[51] L. A. Moutouh-de Parseval, D. Verhelle, E. Glezer et al., "Pomalidomide and lenalidomide regulate erythropoiesis and fetal hemoglobin production in human $\mathrm{CD}_{3} 4^{+}$cells," The Journal of Clinical Investigation, vol. 118, no. 1, pp. 248-258, 2008.

[52] B. A. Miller, S. P. Perrine, A. Bernstein et al., "Influence of steel factor on hemoglobin synthesis in sickle cell disease," Blood, vol. 79, no. 7, pp. 1861-1868, 1992.

[53] U. Wojda, K. R. Leigh, J. M. Njoroge et al., "Fetal hemoglobin modulation during human erythropoiesis: stem cell factor has "late" effects related to the expression pattern of CD117," Blood, vol. 101, no. 2, pp. 492-497, 2003.

[54] M. Gabbianelli, O. Morsilli, A. Massa et al., "Effective erythropoiesis and $\mathrm{HbF}$ reactivation induced by kit ligand in $\beta$ thalassemia," Blood, vol. 111, no. 1, pp. 421-429, 2008.

[55] R. M. Bohmer, "Reactivation of fetal hemoglobin in adult stem cell erythropoiesis by transforming growth factor-beta," Journal of Hematotherapy and Stem Cell Research, vol. 12, no. 5, pp. 499504, 2003.

[56] R. S. Weinberg, X. Ji, M. Sutton et al., "Butyrate increases the efficiency of translation of $\gamma$-globin mRNA," Blood, vol. 105, no. 4, pp. 1807-1809, 2005.

[57] S. P. Perrine, G. Ginder, D. V. Faller et al., "A short-term trial of butyrate to stimulate fetal-globin-gene expression in the $\gamma$ globin disorders," The New England Journal of Medicine, vol. 328, pp. 129-131, 1993.

[58] P. Constantoulakis, G. Knitter, and G. Stamatoyannopoulos, "On the induction of fetal hemoglobin by butyrates: in vivo and in vitro studies with sodium butyrate and comparison of combination treatments with 5-AzaC and AraC," Blood, vol. 74, no. 6, pp. 1963-1971, 1989.

[59] E. Liakopoulou, C. A. Blau, Q. Li et al., "Stimulation of fetal hemoglobin production by short chain fatty acids," Blood, vol. 86, no. 8, pp. 3227-3235, 1995.

[60] A. F. Collins, G. J. Dover, and N. L. C. Luban, "Increased fetal hemoglobin production in patients receiving valproic acid for epilepsy," Blood, vol. 84, no. 5, pp. 1690-1691, 1994.

[61] A. F. Collins, H. A. Pearson, P. Giardina, K. T. McDonagh, S. W. Brusilow, and G. J. Dover, "Oral sodium phenylbutyrate therapy in homozygous $\beta$ thalassemia: a clinical trial," Blood, vol. 85, no. 1, pp. 43-49, 1995.

[62] T. Ikuta, Y. W. Kan, P. S. Swerdlow, D. V. Faller, and S. P. Perrine, "Alterations in protein-DNA interactions in the $\gamma$-globin gene promoter in response to butyrate therapy," Blood, vol. 92, no. 8, pp. 2924-2933, 1998.

[63] G. F. Atweh, M. Sutton, I. Nassif et al., "Sustained induction of fetal hemoglobin by pulse butyrate therapy in sickle cell disease," Blood, vol. 93, no. 6, pp. 1790-1797, 1999.

[64] E. Liakopoulou, Q. Li, and G. Stamatoyannopoulos, "Induction of fetal hemoglobin by propionic and butyric acid derivatives: correlations between chemical structure and potency of $\mathrm{Hb} \mathrm{F}$ induction," Blood Cells, Molecules and Diseases, vol. 29, no. 1, pp. 48-56, 2002.

[65] B. S. Pace, G. L. White, G. J. Dover, M. S. Boosalis, D. V. Faller, and S. P. Perrine, "Short-chain fatty acid derivatives induce fetal globin expression and erythropoiesis in vivo," Blood, vol. 100, no. 13, pp. 4640-4648, 2002.

[66] W. Aerbajinai, J. Zhu, Z. Gao, K. Chin, and G. P. Rodgers, "Thalidomide induces gamma-globin gene expression through increased reactive oxygen species-mediated p38 MAPK signaling and histone $\mathrm{H} 4$ acetylation in adult erythropoiesis," Blood, vol. 110, no. 8, pp. 2864-2871, 2007.

[67] M. Gabbianelli, O. Morsilli, A. Massa et al., "Effective erythropoiesis and $\mathrm{HbF}$ reactivation induced by kit ligand in $\beta$ thalassemia," Blood, vol. 111, no. 1, pp. 421-429, 2008.

[68] R. M. Böhmer, "Reactivation of fetal hemoglobin in adult stem cell erythropoiesis by transforming growth factor- $\beta$," Journal of Hematotherapy and Stem Cell Research, vol. 12, no. 5, pp. 499504, 2003.

[69] A. Guerrini, I. Lampronti, N. Bianchi et al., "Bergamot (Citrus bergamia Risso) fruit extracts as $\gamma$-globin gene expression inducers: phytochemical and functional perspectives," Journal of Agricultural and Food Chemistry, vol. 57, no. 10, pp. 4103-4111, 2009.

[70] E. W. Iyamu, E. A. Turner, and T. Asakura, "In vitro effects of NIPRISAN (Nix-0699): a naturally occurring, potent antisickling agent," British Journal of Haematology, vol. 118, no. 1, pp. 337-343, 2002.

[71] E. W. Iyamu, E. A. Turner, and T. Asakura, "Niprisan (Nix0699) improves the survival rates of transgenic sickle cell mice under acute severe hypoxic conditions," British Journal of Haematology, vol. 122, no. 6, pp. 1001-1008, 2003.

[72] I. Lampronti, D. Martello, N. Bianchi et al., "In vitro antiproliferative effects on human tumor cell lines of extracts from the Bangladeshi medicinal plant Aegle marmelos Correa," Phytomedicine, vol. 10, no. 4, pp. 300-308, 2003.

[73] I. Lampronti, N. Bianchi, M. Borgatti, E. Fibach, E. Prus, and R. Gambari, "Accumulation of $\gamma$-globin mRNA in human erythroid cells treated with angelicin," European Journal of Haematology, vol. 71, no. 3, pp. 189-195, 2003. 
[74] R. Gamabari, "Novel trends for the discovery and characterization of modifiers of globin gene expression," in Proceedings of the 10th International Thalassemia Conference, Cairo, Egypt, May 2009.

[75] E. Fibach, N. Bianchi, M. Borgatti, E. Prus, and R. Gambari, "Mithramycin induces fetal hemoglobin production in normal and thalassemic human erythroid precursor cells," Blood, vol. 102, no. 4, pp. 1276-1281, 2003.

[76] C. Zhang and Z. Wu, "Molecular pharmacological basis of the YiSui ShenXu Granule in $\beta$-thalassemia therapy," Journal of Ethnopharmacology, vol. 120, no. 3, pp. 437-441, 2008.

[77] I. A. Aimola, H. M. Inuwa, A. J. Nok, and A. I. Mamman, "Induction of foetal aemoglobin synthesis in erythroid progenitor stem cells: mediated by water-soluble components of Terminalia catappa," Cell Biochemistry and Function, vol. 32, pp. 361-367, 2014.

[78] S. J. Ameh, F. D. Tarfa, and B. U. Ebeshi, "Traditional herbal management of sickle cell anemia: lessons from Nigeria," Anemia, vol. 2012, Article ID 607436, 9 pages, 2012.

[79] Z. Wu, X. Zhang, and M. Li, "Clinical observation on effects of Yisui Shengxue Granule in treating 156 patients with betathalassemia," Zhongguo Zong Xi Yi Jie He Za Zhi, vol. 26, no. 4, pp. 352-354, 2006.

[80] B. S. Pace, X. Qian, J. Sangerman et al., "p38 MAP kinase activation mediates $\gamma$-globin gene induction in erythroid progenitors," Experimental Hematology, vol. 31, no. 11, pp. 10891096, 2003.

[81] G. Wei, G. Zhao, W. Song et al., "Mechanisms of human $\gamma$-globin transcriptional induction by apicidin involves p38 signaling to chromatin," Biochemical and Biophysical Research Communications, vol. 363, no. 4, pp. 889-894, 2007.

[82] O. Witt, K. Sand, and A. Pekrun, "Butyrate-induced erythroid differentiation of human K562 leukemia cells involves inhibition of ERK and activation of p38 MAP kinase pathways," Blood, vol. 95, no. 7, pp. 2391-2396, 2000.

[83] G. H. Wei, G. W. Zhao, W. Song et al., "Mechanisms of human $\gamma$-globin transcriptional induction by apicidin involves p38 signaling to chromatin," Biochemical and Biophysical Research Communications, vol. 363, no. 4, pp. 889-894, 2007.

[84] M. Politou, P. Kollia, S. Akel, Y. Papassotiriou, A. Stamoulakatou, and D. Loukopoulos, "Valproic acid, trichostatin and their combination with hemin preferentially enhance $\gamma$-globin gene expression in human erythroid liquid cultures," Haematologica, vol. 86, no. 7, pp. 700-705, 2001.

[85] J. J. Barrow, Y. Li, M. Hossain, S. Huang, and J. Bungert, "Dissecting the function of the adult $\beta$-globin downstream promoter region using an artificial zinc finger DNA-binding domain," Nucleic Acids Research, vol. 42, no. 7, pp. 4363-4374, 2014.

[86] W. Shen, D. Liu, and C. Liang, "The regulatory network controlling $\beta$-globin gene switching," Molecular Biology Reports, vol. 28, no. 3, pp. 175-183, 2001.

[87] V. G. Sankaran, J. Xu, and S. H. Orkin, "Advances in the understanding of haemoglobin switching: review," British Journal of Haematology, vol. 149, no. 2, pp. 181-194, 2010.

[88] Y. Nagata, N. Takahashi, R. J. Davis, and K. Todokoro, "Activation of p38 MAP kinase and JNK but not ERK is required for erythropoietin-induced erythroid differentiation," Blood, vol. 92, no. 6, pp. 1859-1869, 1998.

[89] L. Chakalova, C. S. Osborne, Y. Dai et al., "The Corfu $\delta \beta$ thalassemia deletion disrupts $\gamma$-globin gene silencing and reveals post-transcriptional regulation of $\mathrm{HbF}$ expression," Blood, vol. 105, no. 5, pp. 2154-2160, 2005.

[90] R. Mabaera, M. R. Greene, C. A. Richardson, S. J. Conine, C. D. Kozul, and C. H. Lowrey, "Neither DNA hypomethylation nor changes in the kinetics of erythroid differentiation explain 5azacytidine's ability to induce human fetal hemoglobin," Blood, vol. 111, no. 1, pp. 411-420, 2008.

[91] F. Morceau, C. Dupont, V. Palissot et al., "GTP-mediated differentiation of the human K562 cell line: transient overexpression of GATA- 1 and stabilization of the $\gamma$-globin mRNA," Leukemia, vol. 14, no. 9, pp. 1589-1597, 2000.

[92] A. Szulawska, J. Arkusinska, and M. Czyz, "Accumulation of gamma-globin mRNA and induction of irreversible erythroid differentiation after treatment of CML cell line K562 with new doxorubicin derivatives," Biochemical Pharmacology, vol. 73, no. 2, pp. 175-184, 2007.

[93] L. E. Rajagopalan and J. S. Malter, "Regulation of eukaryotic messenger RNA turnover," Progress in Nucleic Acid Research and Molecular Biology, vol. 56, pp. 257-286, 1997.

[94] J. Yuan, E. Angelucci, G. Lucarelli et al., "Accelerated programmed cell death (apoptosis) in erythroid precursors of patients with severe $\beta$-thalassemia (Cooley's anemia)," Blood, vol. 82, no. 2, pp. 374-377, 1993.

[95] E. Angelucci, G. Lucarelli, J. Yuan et al., "Programmed cell death (PCD) and ineffective erythropoiesis in Cooley's anemia," Blood, vol. 88, article 22, 1996.

[96] F. Centis, L. Tabellini, G. Lucarelli et al., "The importance of erythroid expansion in determining the extent of apoptosis in erythroid precursors in patients with $\beta$-thalassemia major," Blood, vol. 96, no. 10, pp. 3624-3629, 2000.

[97] T. J. Ley, J. DeSimone, N. P. Anagnou et al., "5-Azacytidine selectively increases $\gamma$-globin synthesis in a patient with $\beta^{+}$ thalassemia," The New England Journal of Medicine, vol. 307, no. 24, pp. 1469-1475, 1982.

[98] A. W. Nienhuis, T. J. Ley, and R. K. Humphries, "Pharmacological manipulation of fetal hemoglobin synthesis in patients with severe $\beta$-thalassemia," Annals of the New York Academy of Sciences, vol. 445, pp. 198-211, 1985.

[99] D. P. Liu, C. C. Liang, Z. H. Ao et al., "Treatment of severe $\beta$ thalassemia (patients) with myleran," The American Journal of Hematology, vol. 33, no. 1, pp. 50-55, 1990.

[100] S. P. Perrine, B. A. Miller, D. V. Faller et al., "Sodium butyrate enhances fetal globin gene expression in erythroid progenitors of patients with Hb SS and $\beta$ thalassemia," Blood, vol. 74, no. 1, pp. 454-459, 1989.

[101] S. P. Perrine, Y. M. Yang, A. Piga et al., "Butyrate + EPO in beta thalassemia intermedia: interim findings of a phase II trial," Blood, vol. 100, p. 47a, 2002.

[102] H. Fathallah, M. Sutton, and G. F. Atweh, "Pharmacological induction of fetal hemoglobin: why haven't we been more successful in thalassemia?" Annals of the New York Academy of Sciences, vol. 1054, pp. 228-237, 2005.

[103] M. H. Steinberg, Z. Lu, F. B. Barton, M. L. Terrin, S. Charache, and G. J. Dover, "Fetal hemoglobin in sickle cell anemia: determinants of response to hydroxyurea. Multicenter Study of Hydroxyurea," Blood, vol. 89, no. 3, pp. 1078-1088, 1997.

[104] S. Fucharoen, N. Siritanaratkul, P. Winichagoon et al., "Hydroxyurea increases hemoglobin F levels and improves the effectiveness of erythropoiesis in $\beta$-thalassemia/hemoglobin E disease," Blood, vol. 87, no. 3, pp. 887-892, 1996. 
[105] Y.-T. Zeng, S.-Z. Huang, Z.-R. Ren et al., "Hydroxyurea therapy in $\beta$-thalassaemia intermedia: improvement in haematological parameters due to enhanced $\beta$-globin synthesis," British Journal of Haematology, vol. 90, no. 3, pp. 557-563, 1995.

[106] F. M. Hajjar and H. A. Pearson, "Pharmacologic treatment of thalassemia intermedia with hydroxyurea," Journal of Pediatrics, vol. 125, no. 3, pp. 490-492, 1994.

[107] D. Azoulay, A. Lavie, N. Horowitz et al., "A phase 2 study of HQK-1001, an oral fetal haemoglobin inducer, in $\beta$ thalassaemia intermedia," British Journal of Haematology, vol. 164, pp. 451-464, 2014.

[108] Z. Wu, Y. Liu, X. Zhang et al., "Treatment of $\beta$-thalassemia with Bushen Yisui therapy: a randomized controlled trial," Journal of Chinese Integrative Medicine, vol. 5, no. 2, pp. 137-140, 2007. 


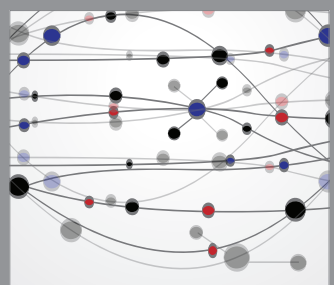

The Scientific World Journal
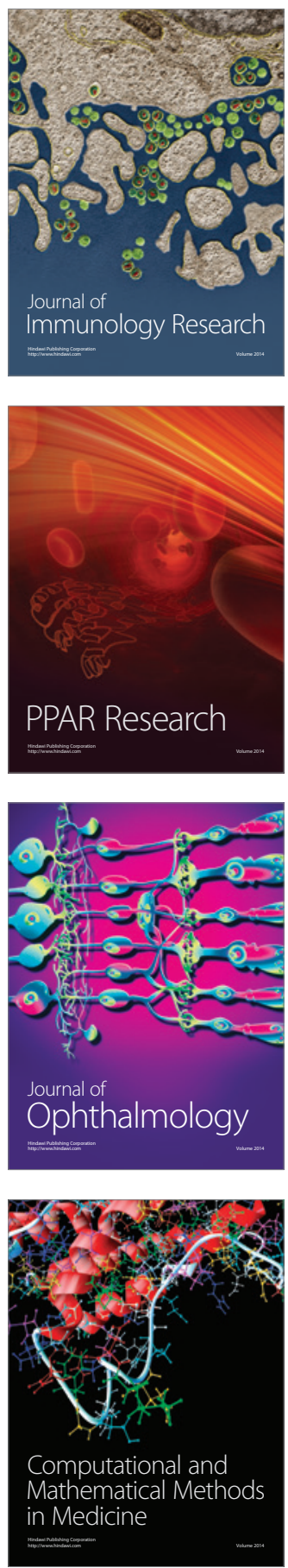

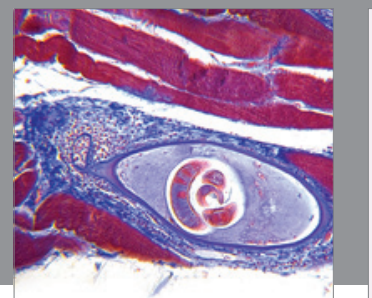

Gastroenterology

Research and Practice
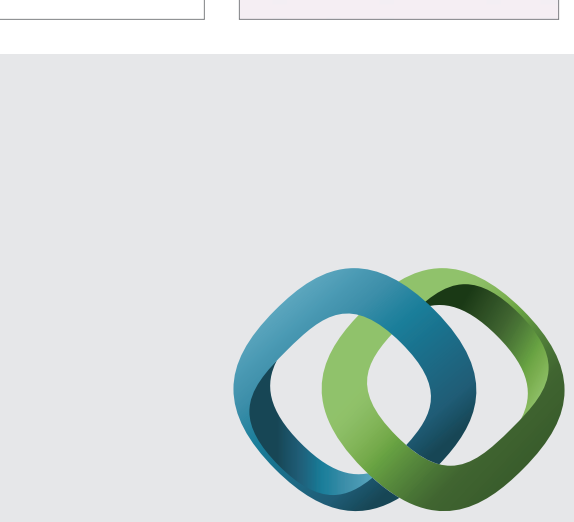

\section{Hindawi}

Submit your manuscripts at

http://www.hindawi.com
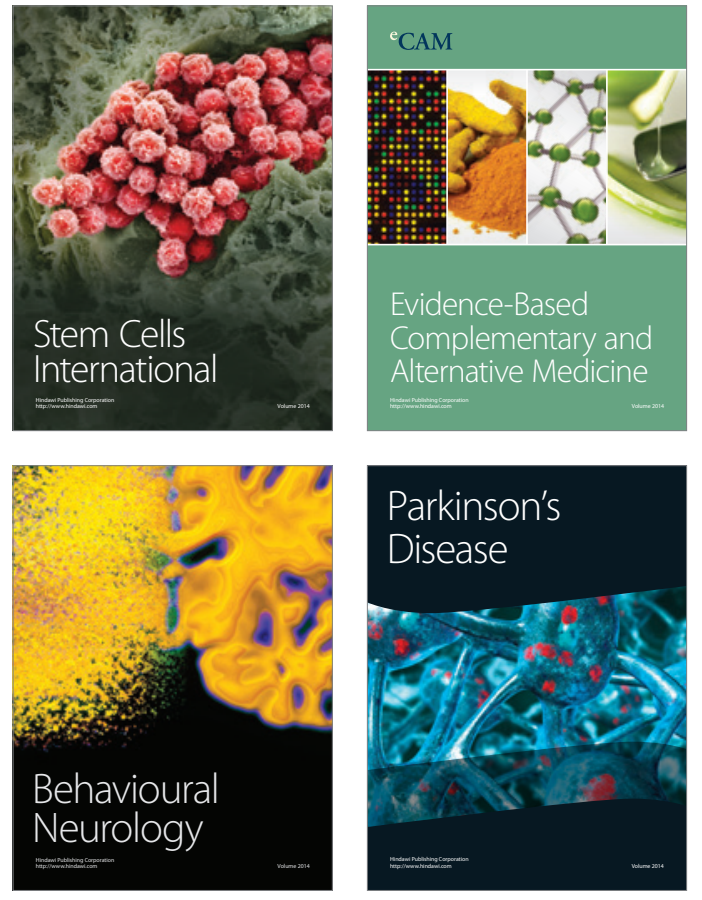
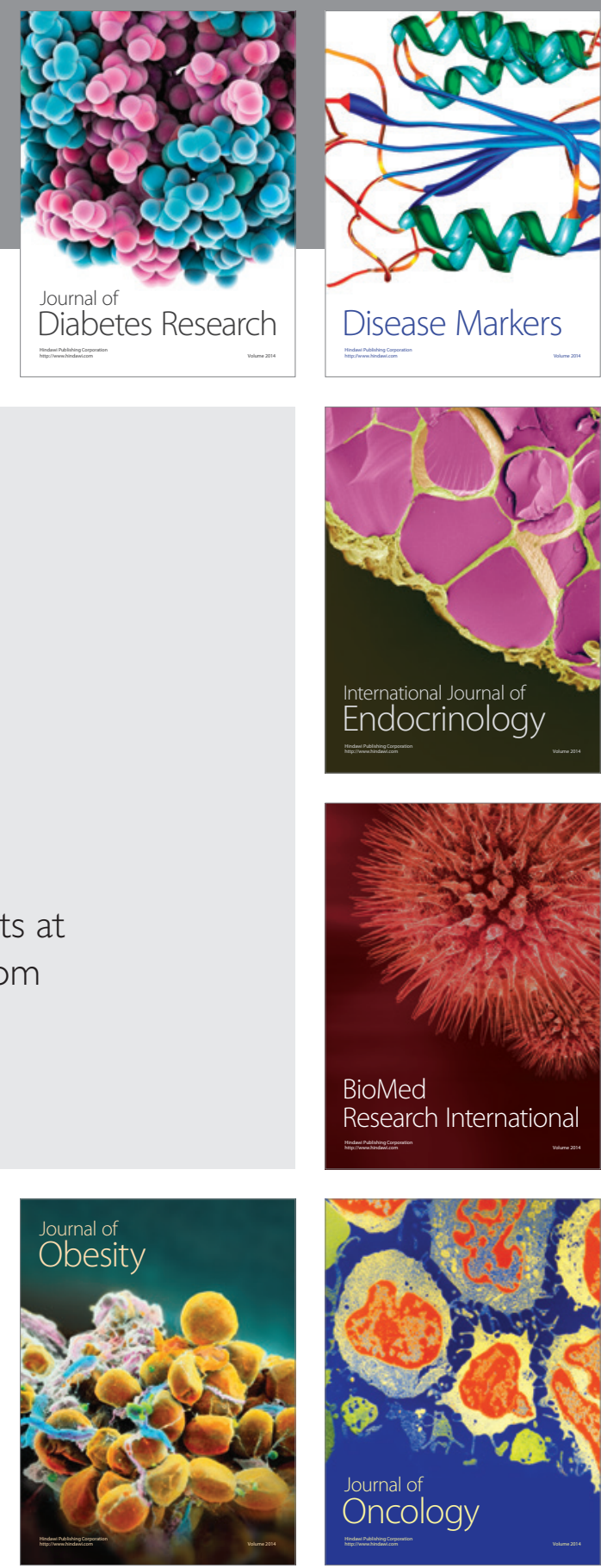

Disease Markers
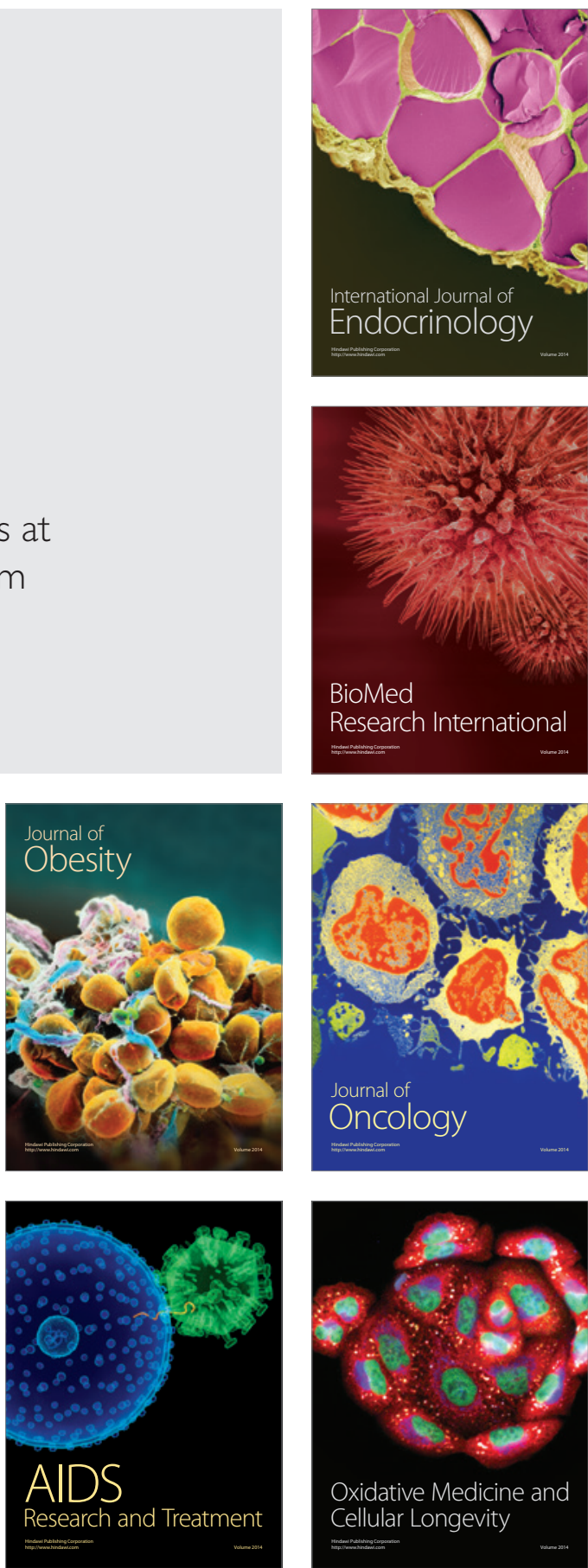